\title{
The soundscape of cities: a new layer in city renewal
}

\author{
M. Leus \\ Department of Design Sciences, \\ Artesis University College Antwerp, Belgium
}

\begin{abstract}
The conservation of historical heritage and the development of public spaces are important issues for the liveability of cities and everyday life. Yet, spatial qualities are rarely designed and evaluated as a combination of senses. Public spaces manifest themselves not only in a visual but also in an acoustic way. Next to the visual aspect of urban spaces, sounds and silence are also indicators of the environmental layout. A sonic urbanity opens a perspective for a better policy with regard to sensorial aspects in design and management of public spaces.

The study of the soundscape of cities is an 'ear-opening' for the multi-sensory qualities of semi-public spaces. Research in which the soundscape is integrated, helps to enhance and emphasize the different components and the underlying historical layers of the city and stimulates the imagination in the construction of narrative tales.

The northern part of the city centre of Antwerp, a remarkable cultural heritage site, is used as a case study to examine different concepts and methods for the implementation of sound in urban development. The research of soundscape in urban planning and heritage management of cultural sites opens up perspectives to create new design paradigms for public spaces.
\end{abstract}

Keywords: soundscape, cultural heritage, experience, sonic concepts, notation tools, communication.

\section{Introduction}

The soundscape of a city is generally marked as something trivial. As a result of contemporary technological noise pollution, urban sounds are often defined as 'unwanted'. Sound pollution, an important form of discomfort, has a negative 
influence on the quality of life in urban public spaces. Sound is rarely used as a positive, informative or explorative social perception instrument within the existing urban planning and heritage management.

The experience of urban public spaces by walking has been studied by several urban researchers but their attention has been mainly focused on the visual aspects or the aesthetic dimension of the spaces [1-4]. Urban designers show a passive acceptance of the aural sound decor. Sound is rarely considered as having a potential contribution in tackling conceptual strategies for the revitalization of urban public spaces [5]. Nevertheless, the experience of the spatial qualities of public spaces is often evaluated by users of these spaces as a combination of senses $[6,7]$.

Due to the static image of urban spaces in contrast to the soundscape which occurs as a dynamic process, consisting of changeable sound waves between the sources and the listener, the urban soundscape is often regarded as complex. The soundscape is four-dimensional and not limited to the material borders of a space; sounds create a kind of an immersive experience space. As Neuhoff pointed out, many cumulative aspects of different sounds influence each other and "changes in one variable may influence the perception of changes in another variable. Changes in any of these perceptual dimensions can influence perception of changes in the others" [8]. Moreover, the experience of soundscape holds different meanings for different people, depending on their cultural and social background, education and previous experience [9].

Although cultural heritage sites offer a valuable contribution towards creating a sustainable environment within the vulnerable continuity of the urban story, sound and heritage, both in their tangible and intangible dimensions, are embodiments of urban places that open space for interpretation. Both project fragments of urbanity and weave them into a scenario by the experience for inhabitants and visitors. Yet, the selection of world heritage sites never demands specific acoustic criteria. Different heritage charters and documents developed at the international level in ICOMOS and UNESCO don't pay special attention to sound as an inherent value of cultural heritage which enhances the experience and interpretation of the historic site.

Acoustic research in relation to urban design requires not only a problemsolving, but also a problem-defining attitude. The most important reason is that planners are lacking an adequate design vocabulary such as aural evocative concepts and tools to integrate an acoustic consciousness in the design process of urban spaces [10]. Yet, communication on soundscape is limited to a conventional semantic language, directed to the physical measurements of urban noise and the description of psychoacoustic parameters [11]. These physical notations are only accessible for those who are trained to decode them. The main question is how a designer can be a composer of a sound performance of the urban space. Or should we rather conclude that a soundscape is an indefinite given that is impossible to orchestrate? 


\section{Aim}

The general objective of this research is to define aural concepts and tools which are applicable during the design process so that urban planners, heritage consultants and architects are able to create public spaces with more sensorial and particular aural qualities. On the one hand this will contribute to the increase of the accessibility of cultural heritage, while on the other hand it will alter the current theoretical urban soundscape discourse. In this way soundscape remains no longer restricted to a recommending theory about noise pollution, but steers applicable keys or strategies for the design process. Aural concepts as a design philosophy provide a base to underpin a deeper cultural meaning that stimulates the interpretation and the interaction with the user and the cultural heritage. Akin argues that "conceptual variables are the schemata that provide the underlying order and structure for an aspect of an architectural design" [12]. Aural concepts can be compared to the soundtrack of a movie, as they both evoke particular emotions and expresses messages [13].

To receive an adequate answer the following questions will be examined:

- How can we map or record a soundscape of a public space as an expressive and significant tool for urban planners and architects?

- How do we conceptualise the aural sense as a perceptual system and how will it be integrated in het design process of urban public spaces.

- How can sounds influence the story of the place, in relation with the cultural heritage?

Although these questions are not self-evident, they are pressure questions that we have to formulate in order to improve the urban fabric.

After explaining the relationship between sound, urban public spaces and cultural heritage, we will also discuss the results of an experimental workshop which explores the sound experience of the urban public space by walking. Heritage is often just a piece of scenery on these walking routes, but sometimes it is the aim of the visit, or a framework for temporary stays, study or entertainment. The hypothesis which we want to test is if soundwalks are useful for the opening-up of cultural heritage.

\section{Synergy between soundscape in urban public spaces and cultural heritage}

The word 'soundscape' covers two important dimensions, namely the relation, on the one hand, between the human being and the sound environment, or the ecological dimension, and the creation and conceptualization of the sound, or the design dimension, on the other hand [14].

Soundscape is also a striking indication of the genius loci, "because the engagement and appreciation of a place depends on the sound the listeners can hear" [15]. Emily Thompson discerns different ways of listening: "A soundscape's cultural aspects incorporate scientific and aesthetic ways of listening, a listener's relationship to their environment, and the social circumstances that dictate who gets to hear what" [16]. Engaged listening 
integrates different aspects of the aural experience. It connects rational as well as emotional aspects. Sounds are the voices of meanings and act as a communicative medium that provides relations charged with emotional and psychological connotations [17].

In his book 'New City Spaces', Jan Gehl distinguishes different types of public spaces: main city squares, recreation squares, promenade squares, traffic squares and monumental squares [18]. From the vision of soundscapes, this typological classification of squares can be completed by adding restorative squares [19]. These tranquil or restorative environments are able to evoke contemplation and support reflective activities [20]. The acoustic quality of a public space largely determines the communication and the experience of sound as an extra source for intensifying and amplifying the visual image, and leads to a better understanding of the genius loci. Sound and silence can break through the artificial classification between tangible and intangible cultural heritage [21]. Mills stated that sound as a social 'agency' can work as a trigger between sender and recipient [22]. Sound communicates information by making people alert and provokes a response of the recipient.

Cultural heritage as well as soundscape is associative rather than linear and relative rather than absolute. Cultural heritage is emotionally charged and based on remembrance and the power to keep memories alive and can be regarded as a stimulus or as an obstacle for general spatial development. The sonic environment stipulates the possibilities for perception of the cultural heritage. Strong sound values can repress the weak historical values. However, when the soundscape matches with the heritage, the cultural values will be amplified. Especially in medieval cities and historic city centres, churches, monasteries, closed building blocks, or palazzos with courtyards have the quality to block the sounds of the city, creating 'silence'. But also narrow streets, mineral surfaces, galleries with vaults, and traditional places, have a particular acoustic quality.

In a positive way, church bells, live music performances, sounds of talking and walking people, sounds of activities in cafés, natural sounds such as singing birds and the rustling leaves, are all considered as the notes of positive soundscapes. Bringing the cultural heritage into urban soundscape-studies offers much potential and enables us to explore 'meanings'.

\section{Research methods}

An experimental interdisciplinary workshop, set up at the public space lab of the Artesis University College of Antwerp, brought together experts from different domains such as architecture, urban planning, art-history and archaeology, in order to discuss their perspectives on the soundscape of urban public spaces. These participants were all experts in the architecture, heritage or urban design.

\subsection{Introspection as a starting point}

The theoretical basis of quantitative acoustic research, which purely defines sound parameters, is too complex for urban planners to get a sufficient image of 
the acoustic experience of a public space [23, 24]. Therefore a qualitative research based on a subjective experimental field study for the survey and analysis of the context was conducted. Nakamura emphasizes that "it is the subjective challenges and subjective skills, not objective ones that influence the quality of a person's experience" [25]. In this workshop, the participants take the user's role and empathize with the user's experiences while walking in urban historical spaces. This approach is based on the idea that the designer's personal experience is a key to acquiring insight, especially in a direct relation with acoustic research by design. Within this framework the acoustic and visual mapping of experiences as well as activities of the visitors and inhabitants plays an important role.

\subsection{Soundwalks}

Because of the ephemeral nature of sound, it is essential for urban designers to think in time dimensions, and to take into account changes, movements and spatial events. Favole pointed out that public urban space is meant to be experienced by walking [26]. Walking as a tuned physical dialogue with the environment explores the experience of listening which offers a stronger sense of community or belonging $[27,28]$. This reflects an affinity with our past. The exploration of soundwalks as developed by Schafer in the seventies is an important valuable tool for aural awareness [29, 30]. Soundwalks, active listening walks, lead to being engaged in the physical and sensory environment and affect the sense of time and place. Järviluoma argued that "Space is a system of places; a place is a space that is special through the meanings connected with it. When we move the places become activated and we enter into a dialogue" [31]. Interpretation connects the sensorial experience with the conceptual idea of meaning $[32,33]$.

\subsection{A cultural perspective of 'modern storytelling' in urban planning}

An interpretive historic research was implemented to report the findings in a narrative story [34]. Linda Groat and David Wang define an interpretive research as "investigations into social, physical phenomena within complex contexts, with a view toward explaining those phenomena in narrative form and in a holistic way" [35]. Especially cultural heritage can act as a mediator. Marc Childs explains that stories can inform and condition the design of places in multiple ways [36]. First of all, urban designers can curate the narratives in ways that support the designers' engagement with place stories; secondly this will activate cycle of interactions between stories and create formats for the inclusion of multiple designers and a diverse set of independent stories.

\subsection{Philosophy of the workshop}

The first step focused on the qualitative survey and analysis of the context, the historical space. The objective was to obtain a deeper understanding of the relation between sound and diverse actors and aspects of the urban environment. 
Therefore a multidimensional reading of space and its qualities was set out by a field study that observed the area in three ways: First the context mapping gathered information of spatial characteristics and the urban development. This spatial analysis resulted in several quick scans: the historical evolution, the cultural heritage, the morphology, functionality, mobility and open and green spaces... These aspects were constantly tested in relation to each other. Secondly, a mapping of behaviour patterns of the visitors and the inhabitants was studied. Thirdly the experience of the urban spaces was incorporated in the research by using a visual and sound mapping. Appraisal of the soundscape depends mainly on the way it matches with the setting [37].

The second step was the study of the historical stratification of the city with special attention for the spatial and temporal links in order to support the interpretive research.

The third step was the expression of the evaluation and interpretation of the current and future situation by means of a postcard with a slogan. Postcards are an attractive medium for communication because they provoke inspirational responses and in a certain way they act as a kind of emotional toolkit. The results of these analyses were translated in plans and sketches so that potential opportunities for new interpretations and development in relation with the vulnerability of the sites were visualized. For this purpose, an appropriate set of instruments was developed by means of the configuration of concepts and soundmapping tools that outline a clear description and typifying illustration of the sonic environment.

\section{Case study: northern part of Antwerp, Belgium}

Yin describes the importance of case studies as follows. "In general, case studies are the preferred strategy when 'how' or 'why' questions are posed, when the investigator has little control over the events, and when the focus is on contemporary phenomena within some real-life context" [38]. The soundscape of the northern part of the city Antwerp was recorded, mapped, assessed and formulated in action items that underpinned the concepts for a sonic urban heritage policy. The historical city centre of Antwerp, located on the right bank of the river Schelde, was indicated with the denominator from MAS, the new museum at the river, to the old central city market. This site is the most representative for the purpose of the survey because a preliminary masterplan revealed the existence of acoustically interesting spots in this area. In addition the site contains cultural heritage par excellence.

\subsection{Notation tools}

The complexity of urban environments demands for new forms of mapping and depiction to enhance urban design and planning. Two notation schemes which are already familiar to the traditional toolkit of depicting urban spaces, represent the aural criteria and make the sonic phenomena communicable and duplicable to support the concepts design process [39]. 
The first notation system shows different diagrams that depict the assessment of the sonic perception in relation to the context. The most important layers of urban experience, the static parameters and the dynamic or temporal sound parameters, were put into radial diagrams, a series of concentric rings associated with increasing intensity of experience. The quality of experience intensifies from the inside to the outside. This graphic notation is a subjective way of mapping the environmental qualities and depicts the relationship between the context, soundtrack and image of each public space. These diagrams give extra value to the acoustic categorization of urban public spaces.

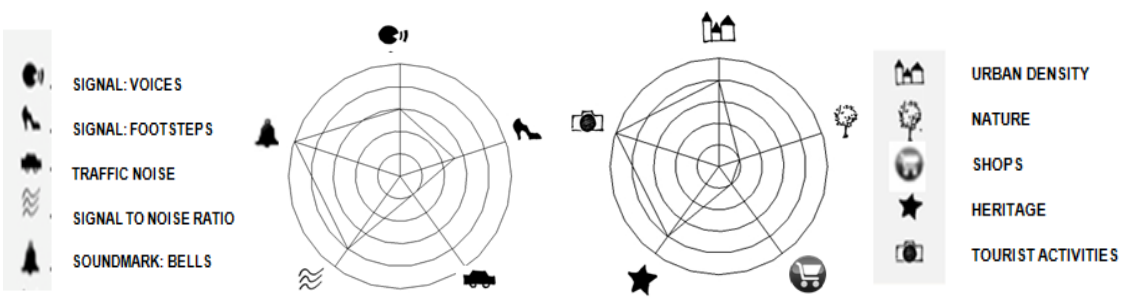

Figure 1: Square of St. Mary's Cathedral: temporal sound parameters context parameters.

A second way of mapping is extracted from the visualization of musicology and geography. For the mapping of soundscape, a sonogram can act as a metaphor for the acoustic environment. A sonogram is a picture drawn by sounds; it articulates a representation of sound waves, which locates the data in frequency, amplitude and time dimensions [40]. This three-dimensional image looks like a geographic landscape and makes the invisible soundscape visible. The variety of a geographic landscape partly determines the attractiveness of it. The same applies to soundscapes where a mixture of sounds characterizes a specific area. This is comparable with the method of representation introduced by Chiambattista Nolli in his ichnographic plan of the city of Rome in 1748, where he accentuated the public spaces both inside and outside [41]. But this icon fails to evoke an impression of complex urban soundscapes, principally because the various sound sources and their loudness or pleasantness are difficult

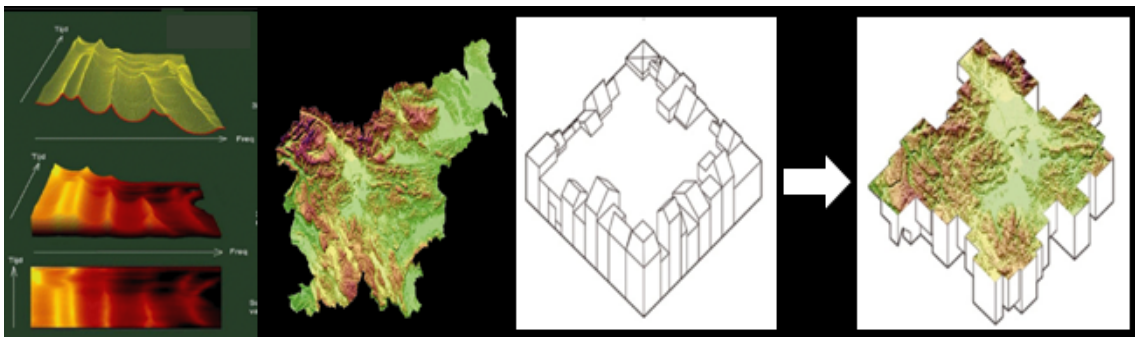

Figure 2: A sonogram, articulating the sounds of public spaces. 
to distinguish. According to synesthetic, which explores the relationship between music and colours, expressing sounds in colours is complicated by personal experiences, which brings out moods and associations [42].

\subsection{Sonic concepts}

Four sonic concepts will highlight different strategies that can be applied to tackle soundscape in current and future plans for sustainable development of urban public spaces. Lucas and Romice emphasize that we should incorporate sound concepts integrally in the drawings that constitute the design process and not as an additional and separate process: "This is due to the way in which drawing is a part of the thinking process itself and not a later representation of an already complete and static idea" [43]. The results of the workshop reveal some emblematic themes which could be transferable to other cityscapes. Therefore we present them as possibly relevant acoustic themes in urban planning.

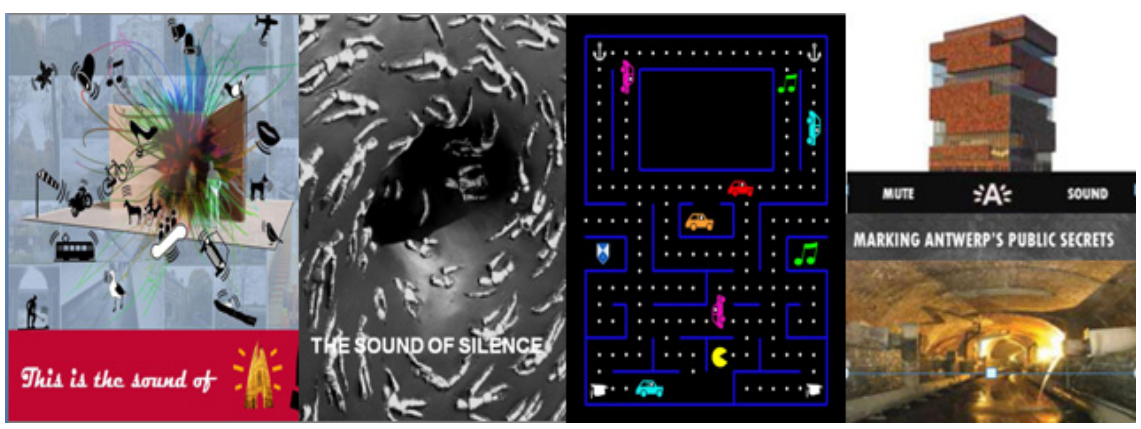

Figure 3: Four sonic concepts: Thresholds, silence, Pac-Man, secrets.

\subsubsection{Concept 1: Soundscape thresholds - a transition between inside-outside}

The oldest historical part of the city around the Central Market is characterised by many public spaces such as the squares of many churches. In this quarter you can explore the music and the historical sounds of the city, such as the bells of the famous Gothic St. Mary Cathedral. The cultural heritage plays an important structuring role in the urban fabric of this quarter; it arranges the soundscape into a harmonious whole, with strong sound contrasts between different areas. In this area, the concept of thresholds or in-between spaces is very important, because thresholds mediate between inside and outside. Sound thresholds and passages in the public spaces are frequently crossed unconsciously [44]. The configuration and materialization of these transition zones offer a frame of significances on a morphological as well as on an acoustic level. Subtle interventions in pavements influence the sound and echo of footsteps and support the experience of entering a different scene. Each passage assumes the presence of a transformation, for example the transformation of a noisy to a quiet area. These are moments in the course of which the city as a whole gets its richness of articulation. The art of 
montage is determined by the significance of the image, the cultural heritage. The same principle can be applied to the sequences of aural fragments [45].

\subsubsection{Concept 2: The magic of secrets spaces}

The area, which borders to the river Schelde, is determined by the presence of water. The workshop revealed the importance of an intrinsically isolated urban space, an amazing network of underground waterways such as covered canals, rivulets and moats and a large pallet of both upper- and underground archaeological heritage. These waterways, dating back to the middle ages, functioned originally as lines of defence while later on they were used as an inland port and as water supply systems. Although covered with archways, these structures explain the structural morphology of the city of Antwerp in a secret way. These underground canals carry a tremendous symbolic meaning. Mystery intersects throughout the various civilizations that left their imprint. The canalhouse or 'Ruihuis', which is situated close to the central market and the MAS, the new museum on the river in the northern part of the city, function as a gate to enter these canals. This concept doesn't represent a submissive position but exposes a sensitive interior world. The interplay of light, dark and sound, silence, echo and resonance are a central theme in this scenographic experience of these underground worlds. The exploration of secrets is incomplete without a glimpse into different layers. The palimpsest of the city covers what is re-inscribed, the metaphor of a chrono-spatial scaffold represents the secrets of this area.

\subsubsection{Concept 3: Pac-Man, an urban labyrinthian game}

This area along the old docklands is a patchwork of old and new and is branded by a jumble of sounds. The chaotic perception of sounds interferes with the old and new cultural heritage. The postcard of this group expresses this vivid quarter with courtyards, formal and semi-public spaces in old monasteries and palazzos, which have been reused as university amenities and which can be compared with a scenery for Pac Man. The Pac-Man concept, as a metaphor for the labyrinthian structure of this area and its soundscape, is inspired by Pacmanhattan, an urban game that stimulates an active listening to the stories of the cultural heritage of New York City [46]. By incorporating play, experience, narration, and social interaction into this game, the players will discover aural scenes on location together with other people. The creation of a partly virtual 'walkabout', a system of routes, referring to the aboriginal's cultural reading of the land, will interweave the soundscape with the legends related to the cultural heritage. In this way, the soundwalk will not only increase the awareness of the soundscape but the game will also motivate the participation in the search for actual sensorial and sustainable cityscapes.

\subsubsection{Concept 4: The sound of silence}

The university neighbourhood, a historical core of the city, displays an intricate network of streets and semi-public spaces. Silence and tranquillity, which are present in the courtyards, the semi public spaces that are part of the university campuses, can reinforce the identity of this area. The beguinage, a walled community that has been entered in 1998 on the list of world heritage is also 
situated in this area. Miller states that silence as soundlessness do not exist. "Silence exists as reference to the ambience of a soundscape, so that quiet and silence become nearly synonymous" [47]. Therefore quiet areas are areas with a good acoustic quality which have a restorative quality. Quiet areas are places where time and space are in touch with each other. The past is generally silent but it is within this silence that the heritage listens and stimulates the imagination in the construction of narrative tales. The human being is the central issue for the opening-up of silent areas [21].

\section{Conclusion}

Within this research the environmental sounds are considered as 'sources of meaning' instead of nuisances. This approach, by which sound is the catalyst for the uploading of the cultural heritage qualities and livability of public spaces, can also bring a new dimension to the 'World Heritage concept'. The soundscape around the world heritage sites is unique and irreplaceable; it supports the universal and outstanding value of this heritage.

Discussions with the participants reveal that the concepts and the notation diagrams offer a structured set of aural information and powerful tools to urban designers and heritage managers. Applying a 'performative lens' will shift the design methodology from conventional notations and concepts dealing with morphology and 'image' to aural sensations including narrative assemblages.

It is impossible to design meaning [48], in the same way as it is impossible to design experience [49]. Orchestrating the soundscape of a city is complicated because it is impossible to examine all the different parameters and their relationship. Like in music there are different ways to orchestrate the same score. The choice of an orchestral scheme also depends on the sound sources, the spatial environment, the activities... An ultimate approach to urban soundscape does not exist because the soundscape and the cultural heritage in the urban context is complex and multiform in character, status, and meaning. Including the soundscape of the cityscape into an urban design supposes a holistic and sustainable approach.

\section{References}

[1] Jacobs, A., Great streets, MIT Press: Cambridge, 1993.

[2] Ching, F., Architecture, Form, Space, and Order, John Wiley \& Sons: New York, 1996.

[3] Isaacs, R., The urban picturesque: an aesthetic experience of urban pedestrian places. Journal of Urban Design, 5, pp. 145-180, 2000.

[4] Brown, B., Werner, C., Amburgey, J. \& Szalay, C., Walkable route perceptions and physical features: converging evidence for en route walking experience. Environment and Behavior, 39, pp. 43-61, 2007.

[5] Durmisevic, S. \& Sariyildiz, S., 2001, A Systematic Quality Assessment of Underground Spaces - Public Transport Stations. Cities, 18(1), pp. 13-23, 2001. 
[6] Rasmussen, S., Experiencing Architecture, MIT Press: Cambridge, 2001.

[7] Pallasmaa, J., The eyes of the skin, Wiley-Academy: Chichester, 2005.

[8] Neuhoff, J.G., Kramer, G. \& Wayand, J., Pitch and loudness interact in auditory displays: Can the data get lost in the map? Journal of Experimental Psychology, 8, 17, 2002.

[9] Southwork, M., The Sonic Environment of Cities. Environment and Behaviour, 1(1), pp. 48-70, 1969.

[10] Blesser, B. \& Salter, L-R., Spaces speak, are you listening? Experiencing aural architecture, MIT Press: Cambridge, 2007.

[11] Raimbault, M. \& Dubois, D., Urban_soundscapes: Experiences and knowledge, Cities, 22(5), pp. 339-350, 2005.

[12] Akin, Ö., Case-based instruction strategies in architecture. Design Studies 23 (4), pp. 410, 2002.

[13] Blumstein, D., Davitian, R. \& Kaye, P., Do film soundtracks contain nonlinear analogues to influence emotion? Biology Letters, 6, pp. 751-754, 2010.

[14] Truax, B., Acoustic Communication, (2nd ed.), CT: Ablex Publishing: Westport, 2001.

[15] Anderson, L., Mulligan, B., Goodman, L. \& Regen, H., Effects of sounds on preferences for outdoor settings. Environment and behavior, 15(5), pp. 539-566, 1983.

[16] Thompson, E., The Soundscape of Modernity, MIT Press: Cambridge, pp. 1-2, 2002.

[17] Labelle, B., Other Acoustics. OASE 78, NAI: Rotterdam, pp. 17, 2009.

[18] Gehl, J. \& Gemzøe, L., New City Spaces, The Danish Architectural Press: Copenhagen, pp. 87, 2001.

[19] Kaplan, R. \& Kaplan, S., The experience of nature: a psychological perspective, University Press: Cambridge, pp. 189, 1989.

[20] Herzog, T. \& Bosley, P., Tranquility and preference as affective qualities of natural environments. Journal of Environmental Psychology, 12, pp. 115127, 1992.

[21] Leus, M., Silence and tranquility areas, the extreme periphery of the inbetween cities, PLIC International conference Public Life in the in-between cities, I.I.T.: Haifa, pp. 93, 2010.

[22] Mills, S., Sensing the place: Sounds and Landscape Archaeology. D.W. Bailey, A. Whittle \& V. Cummings (eds.), (Un)settling the Neolithic, Oxford, pp. 80-81, 2005.

[23] Dubois, D., Guastavino, C. \&Raimbault, M., Les catégories cognitive du bruit urban: des discours aux indicateurs physiques, Acoustique \& Technique, 39, pp. 49-57, 2005.

[24] Schulte-Fortkamp, B., The meaning of annoyance in relation to the quality of acoustic environments. Noise and Health, 4(16) pp. 13-28, 2002.

[25] Nakamura, J. \& Csikszentmihalyi, M., The concept of flow. Handbook of Positive Psychology, eds. C. Snyder \& S. Lopez, pp. 92, 2005.

[26] Favole, P., Squares in Contemporary Architecture, The Architectura \& Natura Press: Amsterdam, 1995. 
[27] Ansdell, G., Rethinking music and community: Theoretical perspectives in support of community music therapy. Community music therapy, eds. M. Pavlicevic \& G. Ansell, Jessica Kingsley Publishers: London \& Philadelphia, pp. 91-113, 2004.

[28] Fiumara, G., The other side of language: A philosophy of listening, Routledge: London and New York, 2006.

[29] Schafer, M., The Tuning of the World, Knopf: New York, 1977.

[30] Kang, J. \& Zhang, M., Semantic differential analysis of the soundscape in urban open public spaces. Building and Environment, 45(1) , pp. 150-157, 2010.

[31] Järviluoma, H., Truax, B., Kyto, M. \& Vikman, N., (Eds.), Acoustic Environments in Change. Tampere: University of Joensuu: Tampere, 2009.

[32] Saipradist, A., A critical analysis of heritage interpretation and the development of a guidebook for non-Thai cultural tourists at Ayuthaya World Heritage site, Unpublished PhD, Silpakorn University: Bangkok, 2005.

[33] Crowest, R., Multisensory interpretation and the Visitor Experience, Dissertation submitted in partial fulfillment of the requirements of the Degree of MA, Heritage Interpretation, University of Surrey: Strawberry Hill, 1999.

[34] Collingwood, R., The Idea of History, Oxford University Press: London and New York, 1956.

[35] Groat, L., \& Wang, D., Architectural research methods, John Wiley \& Sons: New York, pp. 136, 2002.

[36] Childs, M., Storytelling and urban design. International Research on Placemaking and Urban Sustainability, Journal of Urbanism: 1754-9183, 1(2), pp. 173 - 186, 2008.

[37] Carles, J., Lopez Barrio, I. \& Vicente de Lucio, J., Sound influence on landscape values, Landscape and urban planning 43, pp. 191-200, 1999.

[38] Yin, R., Case study research: Design and methods, Applied Social Research Methods Series (3rd ed.) 5, SAGE Publications: Thousand Oaks, CA, 2003.

[39] Lawson, B., How Designers Think: The design process demystified ( $3^{\text {rd }}$ ed.) Architectural Press: Oxford, 2000.

[40] Lidy, T. \& Rauber, A., Classification and Clustering of Music for Novel Music Access Applications. Machine Learning Techniques for Multimedia", M. Cord, P. Cunningham (Hrg.), Springer: Berlin Heidelberg, 2008.

[41] Leupen, B., Grafe, C., Körnig, N., Lampe, M. \& de Zeeuw, P., Design and Analysis, 010 Publishers: Rotterdam, 1997.

[42] Asmus, E., The measurement of musical expression. Paper presented at the Suncoast Music Education Research Symposium, Tampa, Florida, 2009.

[43] Lucas, R. \& Romice, O., Representing Sensory Experience in Urban Design. Design Principles and practices: an International Journal, 2(4), pp. 83, 2008. 
[44] Van Eyck, A. \& Hertzberger, H., Drempel en ontmoeting: de gestalte van het tussen, (threshold and encounter, the shape of in- between, Forum (8), pp. 248-251, 1959.

[45] Brillenburg Wurth, K., The Musicality of the Past: Sehnsucht, Trauma, and the Sublime. Journal of the Philosophy of History, 1(2), pp. 219-247, 2007.

[46] PACMANHATTAN, http://pacmanhattan.com

[47] Miller, W., Silence in the Contemporary Soundscape. MA Thesis, Department of Communications, Simon Fraser University: Burnaby, 1993.

[48] Berlo, D., Process of Communication: An Introduction to Theory and Practice. Holt, Rinehart and Winston: New York, 1960.

[49] Thackara, J. Articles of Association Between Design, Technology and The People Formerly Known As Users. Doors of Perception, 2000. www.doorsofperception.com 